(C) 2019 IEEE. Personal use of this material is permitted. Permission from IEEE must be obtained for all other uses, in any current or future media, including reprinting/republishing this material for advertising or promotional purposes, creating new collective works, for resale or redistribution to servers or lists, or reuse of any copyrighted component of this work in other works. 


\title{
Study on Segmented-Rotor Switched Reluctance Motors With Different Rotor Pole Numbers for BSG System of Hybrid Electric Vehicles
}

\author{
Xiaodong Sun, Senior Member, IEEE, Kaikai Diao, Student Member, IEEE, \\ Gang Lei, Member, IEEE, Long Chen, Youguang Guo, Senior Member, IEEE, \\ and Jianguo Zhu, Senior Member, IEEE
}

\begin{abstract}
This paper investigates the design principles and performance optimization for segmented-rotor switched reluctance motors (SRSRMs) with different rotor pole numbers for belt-driven starter generators of hybrid electric vehicles. For the design principles, several constraints are derived for the numbers of stator and rotor poles, the dimensions and the number of winding turns. Two SRSRMs with $16 / 10$ and $16 / 14$ stator/rotor poles are presented according to these principles. For the performance optimization, the two motors are optimized individually for maximizing the torque. To evaluate the effect of different segmented-rotor numbers, the overall performances of the two SRSRMs are investigated and compared. It is found that the 16/14 SRSRM has higher flux linkage and static torque. The 16/14 SRSRM exhibits higher torque and lower torque ripple at low speed operation. While at high speed, the 16/10 SRSRM performs better in torque and power densities. Compared with the 16/14 SRSRM, the 16/10 SRSRM has higher final steady speed under the same startup condition. The 16/10 SRSRM can achieve higher steady speed under starter mode, and provide higher generated power under braking mode. Moreover, the 16/10 SRSRM exhibits higher efficiency in the most feasible speed range, especially in high speed range, and it has wider high-efficiency area. Finally, a 16/10 SRSRM is prototyped and tested to validate the simulation results.
\end{abstract}

Index Terms-Finite-element analysis, optimization, rotor pole number, segmented-rotor, switched reluctance motor.

Copyright (c) 2019 IEEE. Personal use of this material is permitted. However, permission to use this material for any other purposes must be obtained from the IEEE by sending a request to pubspermissions@ieee.org.

Manuscript received October 23, 2018; revised February 02, 2019 and March 18, 2019; accepted April 22, 2019. This work was supported by the National Natural Science Foundation of China under Projects 51875261 and U1564201, the Natural Science Foundation of Jiangsu Province of China under Projects BK20180046 and BK20170071, the "Qinglan project" of Jiangsu Province, the Key Project of Natural Science Foundation of Jiangsu Higher Education Institutions under Project 17KJA460005, and the Six Categories Talent Peak of Jiangsu Province under Project 2015-XNYQC-003. (Corresponding author: Gang Lei.)

\begin{tabular}{ll}
$u$ & \multicolumn{1}{c}{ NoMENCLATURE } \\
$\omega$ & Voltage \\
$\alpha_{r}$ & Angular speed of the rotor \\
$\alpha_{s}$ & Rotor pole arc coefficient \\
$\beta_{s}$ & Excited stator pole arc coefficient \\
$\beta_{r}$ & Excited stator pole arc \\
$\theta_{o n}, \theta_{o f f}$ & Rotor pole arc \\
$\theta_{s}, \theta_{r}$ & Turn-on and turn-off angles \\
$A$ & Stator and rotor pole pitch angles \\
$B_{\delta}$ & The electrical load \\
$D_{a}$ & Flux density at the commutation position \\
$k$ & Rotor outer diameter \\
$l_{a}$ & Empirical coefficient related to the phase \\
$N_{p h}$ & current \\
$N_{r}$ & Stack length \\
$N_{s}$ & Phase number \\
$n$ & The number of rotor poles \\
$P_{e m}$ & The number of stator poles \\
& Rotor speed.
\end{tabular}

\section{INTRODUCTION}

Towadays, the research and development of hybrid electric 1 vehicles (HEVs) is very urgent due to the environmental pollution and the shortage of the oil resources [1]-[4]. There are three typical models of HEV system, which are belt-driven starter generators (BSGs), integrated starter generators (ISGs), and fully mixed drive motor and generator systems [5].

X. Sun, K. Diao, and L. Chen are with the Automotive Engineering Research Institute, Jiangsu University, Zhenjiang 212013, China (email: xdsun@ujs.edu.cn, diaokaikai@163.com, chenlong@ujs.edu.cn).

G. Lei and Y. Guo are with the School of Electrical, Mechanical, and Mechatronic Systems, University of Technology Sydney, NSW 2007, Australia (e-mail: Youguang.Guo-1@uts.edu.au, Gang.Lei@uts.edu.au).

J. Zhu is with the School of Electrical and Information Engineering, University of Sydney, NSW, 2006, Australia (e-mail: jianguo.zhu@sydney.edu.au). 
Compared with the other two types of typical models, BSGs reduce the fuel consumption and emissions. In [6], a belt-driven induction starter-generator is presented, but it has low efficiency at high speed. On the other hand, the belt-driven permanent-magnet starter-generator is easy to be demagnetized under high temperature. Besides, the cost of the permanent magnet material is very high [7]. Compared with the induction machines and permanent-magnet machines for BSGs, switched reluctance motors (SRMs) have attracted much attention in electric vehicle applications due to their high fault tolerance, low manufacturing cost and high efficiency in a wide range of speed [8]. They also suffer from many inherent drawbacks, such as high torque ripple and low torque density, which limit their applications in industry [9]. In order to increase the torque density and decrease the torque ripple, a variety of configurations have been investigated for SRMs, including two main categories, segmented-stator SRMs (SSSRMs) and segmented-rotor SRMs (SRSRMs).

The most commonly used structures in SSSRMs are the Ecore and C-core structures. Lee et al. proposed a novel twophase SRM with a stator of E-core structure, which appears to have good manufacturability, mechanical robustness, and minimum stator core iron [10], [11]. In [12], an E-core 6/10 SRM with a short-flux was modified to produce higher torque. The average torque of the proposed SRM after modification was increased by about 35\%. In [13], two novel three-phase SRMs with hybrid magnetic paths comprising six E-shaped modular stators and three segmented-rotors were proposed and analyzed. In [14], an SSSRM with C-core stator was presented to further simplify the manufacturing and repairing process. The windings are wound around the yoke of the stator segments and the proposed motor can operate at a continuous speed despite five severe winding fault conditions. Moreover, based on the E-core stator, a novel SRM was designed using the distinct concepts including design considerations of salient poles and the motor energy conversion capacity [15]. This motor has six segments in the stator with four poles.

The SRSRMs were firstly proposed in 2004 [16]. Two threephase designs were considered, one with windings spanning across a number of teeth, and the other with a single tooth span. It was found that both the motors can produce over $40 \%$ more torque than a conventional SRM with the same dimensions. In [17], a novel 6/5 SRSRM was presented and two types of stator poles, i.e., excited and auxiliary poles, were introduced. It is proved that the proposed structure increases the electrical utilization. A strategy was developed to optimize the SRSRM in order to achieve the maximum efficiency in [18]. The optimization combined both static and dynamic performance across different regions of the torque speed envelope. In [19], an SRSRM was presented and the effect of stator slot/rotor segment combination was investigated. Such SRSRMs with higher number of rotor segments than stator slots have higher efficiency and torque output but lower overload capability. Similar conclusions can be found in [20], which emphasized that SRSRMs with a greater number of rotor segments than stator poles provide significant benefits at low speed and current excitation. In addition, most of the axial motors use the segmented-rotor structure due to the limits of space. For example, a novel axial SRM with a high number of rotor segments was analyzed and manufactured in [21].

In order to research the new segmented structures of SRMs, much attention has been paid to the effect of the numbers of stator or rotor poles on the performance of the new motors. In [22], Bilgin et al. presented the advantages for a novel SRM configuration with higher number of rotor poles than stator poles, such as greater torque characteristics and lower ripple. In [23], SRMs combining segmented structure and PMs with different rotor poles were investigated. It is presented that the 12/10 segmented-stator hybrid-excitation SRM exhibits better characteristics than the 12/8 segmented-stator hybrid-excitation SRM, such as higher dynamic average torque and lower torque ripple. The research about SRMs with higher number of rotor poles than stator poles was further conducted in [24]. It is proved that these configurations with comparable number of phases, without the need for special power electronic circuit, exhibit superior performance, such as higher torque density and lower manufacturing costs, than the conventional SRMs.

Though a few literatures have investigated the effect of different segmented-rotor pole numbers on the performance of SRSRMs [19], [20], comprehensive design process and overall performance comparisons on the effect of different rotor pole numbers are not yet reported. Several characteristics including startup performance and efficiency analysis, which are essential to industry application, have not been reported. In this paper, the general design principles will be investigated for SRSRMs. Two four-phase SRSRMs with $16 / 10$ and 16/14 stator/rotor poles will be presented and compared through optimization according to those principles. The idea is inspired by the work about SRSRM in [25] and [26], which mainly focus on the design and analysis of the SRSRM. The remainder of this paper is organized as follows. Section II presents the main design principles for SRSRMs. Section III conducts the optimization for those two SRSRMs. The overall performances of two SRSRMs are compared in Sections IV and V, respectively. Experimental verification is given in Section VI, followed by the conclusions.

\section{DESIGN PRINCIPLES OF SRSRMS}

Fig. 1 shows the topologies of the proposed SRSRMs with $16 / 10$ and 16/14 stator/rotor poles. As shown, both motors have 16 stator poles. The stator has two types of poles: excited poles and auxiliary poles. The excited poles are wound by windings, while the auxiliary poles are only functioned as flux return paths without any windings. The rotor contains a series of discrete segmented rotors, and each component is embedded in the nonmagnetic isolator.

Both SRSRMs have the same winding configurations and connections. Each motor has four phase windings, and each phase winding consists of two coils wound on the two opposite poles of stator, and the windings in the two opposite poles are connected in parallel. In Fig. 1(a), the rotor of the 16/10 SRSRM will rotate counterclockwise with the phase current energized in the sequence of $\mathrm{ABCD}$. On the contrary, the rotor of the 16/14 SRSRM will rotate clockwise with the same 
sequence. The specifications of the BSG machine are listed in Table I. The voltage of the battery is $14 \mathrm{~V}$, and it has been increased to $60 \mathrm{~V}$ by the convertor for the power converter as the SRSRM requires higher constant voltage excitation.

Some design rules should be followed for the effective design of SRSRMs. Five design principles are discussed as follows for the stator/rotor pole numbers and dimensions.

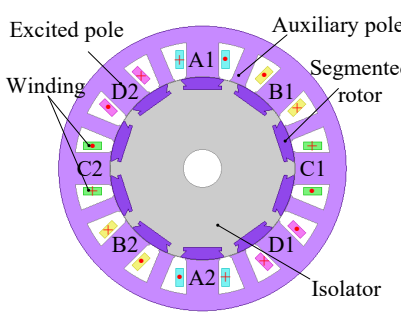

(a)

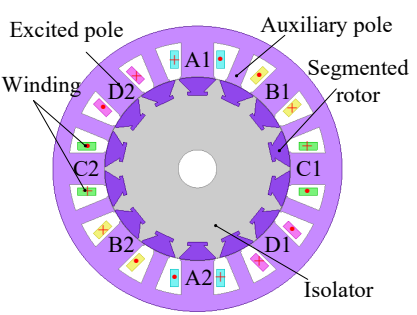

(b)
Fig. 1. Configuration of SRSRMs. (a) $16 / 10$ poles. (b) $16 / 14$ poles.

TABLE I

SPECIFICATIONS OF THE BSG MACHINE

\begin{tabular}{ccc}
\hline \hline Parameters & Unit & value \\
\hline Rated power & $\mathrm{kW}$ & 1.8 \\
Rated speed & $\mathrm{r} / \mathrm{min}$ & 6000 \\
Maximum speed & $\mathrm{r} / \mathrm{min}$ & 15600 \\
Rated voltage & $\mathrm{V}$ & 60 \\
Transmission ratio of belt pulley & - & $2.7: 1$ \\
Startup torque & $\mathrm{Nm}$ & $>24$ \\
Startup time & $\mathrm{S}$ & $<0.5$ \\
Efficiency & - & 0.85 \\
\hline \hline
\end{tabular}

\section{A. Numbers of stator and rotor poles}

Different from the rule for the conventional SRM [29], the numbers of stator and rotor poles in an SRSRM should follow

$$
\operatorname{LCM}\left(\frac{1}{2} N_{\mathrm{s}}, N_{r}\right)=N_{p h} N_{r}
$$

where $L C M$ means the least common multiple. It should be noted that this rule is different from that required by the conventional SRM due to the two types of the stator poles.

\section{B. Rotor outer diameter and stack length}

The relationship between the rotor outer diameter $D_{a}$ and the stack length $l_{a}$ is expressed as

$$
\lambda=l_{a} / D_{a}
$$

where $\lambda$ is the ratio of $l_{a}$ and $D_{a}$. Normally, $\lambda=0.5 \sim 3$.

Furthermore, the two dimensions, $D_{a}$ and $l_{a}$, can be estimated by the following equation [30].

$$
D_{a}^{2} \cdot l_{a}=k \cdot \frac{6.1 P_{e m}}{B_{\delta} A n}
$$

\section{Stator and rotor pole arcs}

The auxiliary stator pole arc is equal to half of $\beta_{s}$, since two adjacent auxiliary stator poles carry the return flux of one excited stator pole. Limited by the space, $\beta_{s}$ and $\beta_{r}$ should satisfy the following equations

$$
\left\{\begin{array}{l}
\frac{3 \beta_{s}}{4}<\frac{2 \pi}{N_{s}} \\
\beta_{r}<\frac{2 \pi}{N_{r}}
\end{array} .\right.
$$

In order to meet the requirement that the proposed SRSRMs are able to start up in the positive or negative direction at any rotor position and obtain the ideal maximum inductance, $\beta_{s}$ and $\beta_{r}$ are also constrained by the following equation

$$
\frac{2 \pi}{N_{r}}-\beta_{r} \leq \beta_{s} \leq \beta_{r} .
$$

In this paper, the SRSRM is designed to be a four-phase motor. Firstly, the number of the stator poles is selected as sixteen. According to (1), the number of rotor poles can be chosen as six, ten, fourteen, or even more. However, considering (4) and (5), if the number of rotor segments is too small, the leakage flux is serious and the motor will have poor startup ability due to the large angle between the two adjacent segmented-rotors. If the number of rotor segments is larger than fourteen, the rotor pole arc $\beta_{r}$ is too small to meet the requirements. Thus, two good options for the number of rotor segments are 10 and 14.

\section{Segmented rotor radial height}

Most flux lines pass through the segmented-rotor in SRSRMs, thus the radial height of the segmented-rotor $\left(h_{c r}\right)$ will influence the flux density of the rotor. When the motor is at the aligned position, the magnetic circuit is divided into two paths at the air gap, so the angle occupied by each path at the rotor outer diameter is $\left[\beta_{s^{-}}\left(2 \pi / N_{r}-\beta_{r}\right)\right] / 2$. When the motor is at the unaligned position, the angle occupied by each path at the rotor outer diameter is $\beta_{s} / 2$. Then, the value of $h_{c r}$ is constrained by

$$
\mu_{1} \cdot \frac{\beta_{s}-\left(2 \pi / N_{r}\right)}{2} \leq h_{c r} \leq \mu_{2} \cdot \frac{\beta_{s}}{2}
$$

where $\mu_{1}$ and $\mu_{2}$ are the factors, $\mu_{1}<1$, and $\mu_{2}>1$.

\section{E. Number of turns per pole, $N$}

The number of turns per pole is expressed by the following equation [30].

$$
N=\frac{N_{r} u\left(\theta_{\text {off }}-\theta_{\text {on }}\right)}{\omega B_{\delta} D_{a} l_{a} \pi}=\frac{3.04 N_{r} u\left(\theta_{\text {off }}-\theta_{\text {on }}\right)}{n B_{\delta} D_{a} l_{a}}
$$

\section{OPTIMIZATION OF SRSRMS}

Through the magnetic equivalent circuit analysis, it is found that the performances of SRSRMs including inductance, torque and current highly depend on three parameters, the excited stator pole $\operatorname{arc} \beta_{s}$, the rotor pole $\operatorname{arc} \beta_{r}$, and the segmented-rotor radial height $h_{c r}$ [27], [28].

\section{A. Optimization of pole arc coefficients}

The excited stator pole arc $\beta_{s}$ and rotor pole arc $\beta_{r}$ can be represented by using the excited stator pole arc coefficient $\alpha_{s}$ and rotor pole arc coefficient $\alpha_{r}$, respectively.

$$
\left\{\begin{array}{l}
\alpha_{s}=\beta_{s} / \theta_{s} \\
\alpha_{r}=\beta_{r} / \theta_{r}
\end{array}\right.
$$


The ranges of the pole arc coefficients are estimated according to (4), (5) and (8). The optimization of $\alpha_{s}$ and $\alpha_{r}$ for the $16 / 10$ and 16/14 SRSRMs are carried out as follows.

Figs. 2 and 3 show the values of static torque under different combinations of the pole coefficients with different current values for the $16 / 10$ and 16/14 SRSRMs, respectively. The stator pole arc coefficient of the two motors ranges from 0.85 to 0.95 with a step size of 0.01 . The rotor pole arc coefficient of the two motors ranges from 0.66 to 0.86 with a step size of 0.02 . As shown in Fig. 2, the torque increases with the enlargement of the excited stator pole arc coefficient. The torque reaches the minimum value when the rotor pole arc is 0.7 , then rises quickly from 0.7 to 0.74 , and keeps fluctuating in the range of 0.74 to 0.84 , and finally drops in the range of 0.84 to 0.86 . Therefore, for the 16/10 SRSRM, the best value of $\alpha_{s}$ can be selected as 0.95 , and the best value of $\alpha_{r}$ should be selected between 0.74 and 0.84 . Considering the structural stability of isolator and the cost, $\alpha_{r}$ is selected as 0.74 at last. Similar conclusions can be drawn for the 16/14 SRSRM from Fig. 3. Finally, the value of $\alpha_{s}$ is selected as 0.95 , and the value of $\alpha_{r}$ is selected as 0.84 . (a)

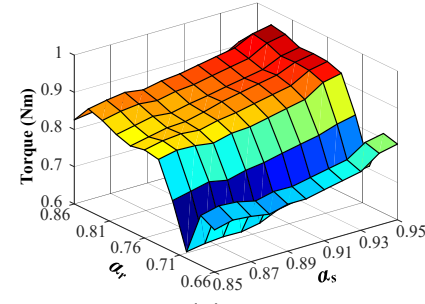

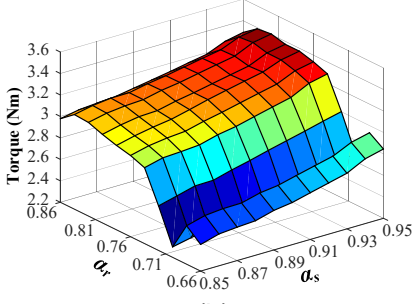

(b)
Fig. 2. Relationship between static torque and pole arc coefficients of the $16 / 10$ SRSRM. (a) $i=15$ A. (b) $i=30$ A.

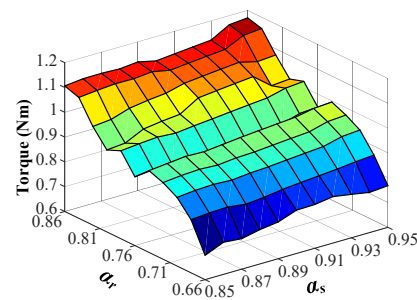

(a)

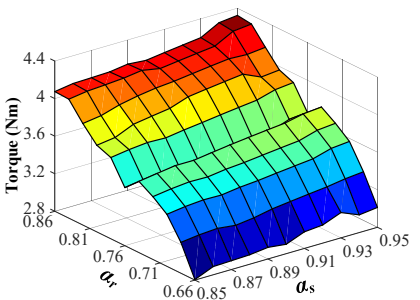

(b)
Fig. 3. Relationship between static torque and pole arc coefficients of the $16 / 14$ SRSRM. (a) $i=15$ A. (b) $i=30$ A.

After the optimization of $\alpha_{s}$ and $\alpha_{r}$, it can be found that the $16 / 10$ and $16 / 14$ SRSRMs have the same structure of stator, so it is feasible to have the same winding arrangements.

\section{B. Optimization of segmented-rotor radial height}

The segmented-rotor radial height $h_{c r}$ is crucial for the motor performance as it will affect the flux density of the segmentedrotor. The relationship between static torque and segmentedrotor radial height of the 16/10 motor is illustrated in Fig. 4. As shown in Fig. 4(a), when the current is $15 \mathrm{~A}$, the torque decreases when $h_{c r}$ ranges from 4 to $9 \mathrm{~mm}$, and then increases. In Fig. 4(b), with the current of $30 \mathrm{~A}$, the torque achieves the maximum value when $h_{c r}$ is $5.5 \mathrm{~mm}$. Thus, considering the two figures, $h_{c r}$ for the $16 / 10$ SRSRM is finally taken as $5.5 \mathrm{~mm}$.
Fig. 5 reflects the relationship between static torque and segmented-rotor radial height of the 16/14 SRSRM. The torque achieves the maximal value when $h_{c r}$ is $8 \mathrm{~mm}$ with $15 \mathrm{~A}$, as shown in Fig. 5(a). The curve in Fig. 5(b) is similar to that in Fig. 5(a), thus, considering the two figures, $h_{c r}$ for the $16 / 14$ SRSRM is finally taken as $8 \mathrm{~mm}$.

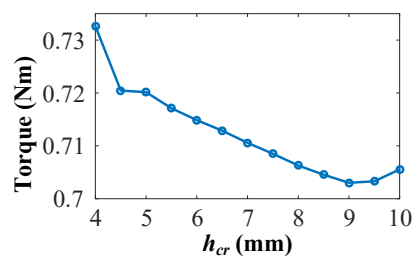

(a)

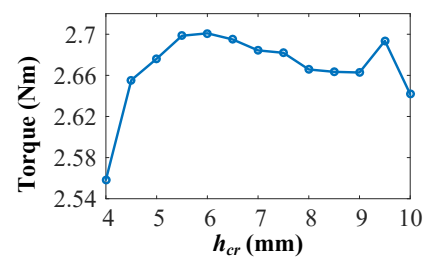

(b)
Fig. 4. Relationship between static torque and segmented-rotor radial height of the $16 / 10$ SRSRM. (a) $i=15 \mathrm{~A}$. (b) $i=30 \mathrm{~A}$.

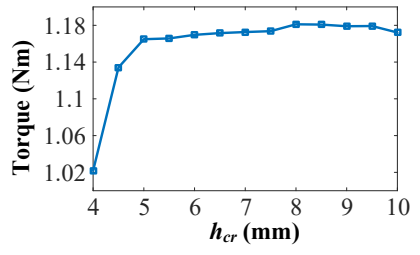

(a)

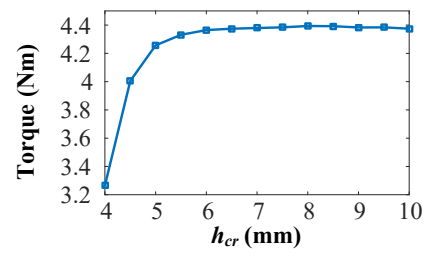

(b)
Fig. 5. Relationship between static torque and segmented-rotor radial height of the $16 / 14$ SRSRM. (a) $i=15 \mathrm{~A}$. (b) $i=30 \mathrm{~A}$.

After the optimization, the main dimensions and parameters of the two SRSRMs are listed in Table I. The electrical steel material for the stator and rotor is DW310, and its B-H curve is shown in Fig. 6.

TABLE II

Key PARAMETERS AND Dimensions OF Two SRMs

\begin{tabular}{lcc}
\hline \hline Parameter & $16 / 10$ & $16 / 14$ \\
& SRSRM & SRSRM \\
\hline Phase number & 4 & 4 \\
Rated speed (r/min) & 6000 & 6000 \\
Stator outer diameter (mm) & 128 & 128 \\
Axial length (mm) & 80 & 80 \\
Rotor outer diameter (mm) & 82 & 82 \\
Stator yoke width (mm) & 7 & 7 \\
Rotor yoke width (mm) & 5.5 & 8 \\
Excited/auxiliary stator pole arc coefficients & $0.95 / 0.475$ & $0.95 / 0.475$ \\
Rotor pole arc coefficient & 0.74 & 0.84 \\
Air gap length (mm) & 0.25 & 0.25 \\
Shaft diameter (mm) & 17 & 17 \\
Number of turns in each pole & 24 & 24 \\
Electric steel material & DW310 & DW310 \\
\hline \hline
\end{tabular}

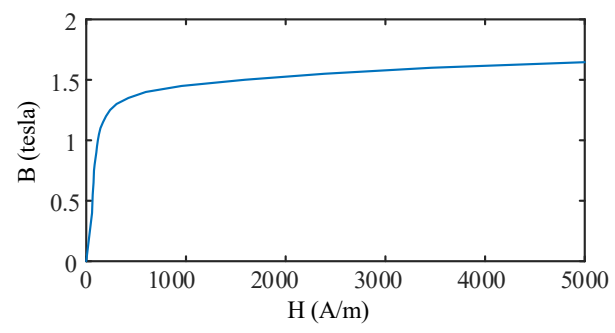

Fig. 6. The BH curve of the material DW310. 


\section{MAgnetic Characteristics}

In order to evaluate the magnetic characteristics of the two SRSRMs, a comparison is made through finite-element analysis (FEA) in this section. To achieve a fair comparison, the two SRSRMs have the same outer size, electric steel material, air gap, winding connections, and number of turns in each pole. The main differences are the segmented-rotor pole numbers and the values of optimization parameters listed in Table I.

\section{A. Magnetic field distributions}

Fig. 7 illustrates the flux density of two motors at aligned position when one phase is excited with $30 \mathrm{~A}$. As shown, the $16 / 10$ and 16/14 SRSRMs have similar flux distribution. At the aligned position, the magnetic flux flows down from the excited stator pole, through the segmented-rotor and returns via the adjacent auxiliary poles. All the conductors in each slot only couple with the flux driven by their phase windings with a few mutual coupling between adjacent slots, which can increase the electrical utilization. The major difference in the flux density of the two figures is at the tooth tip of the excited stator poles and the corresponding segmented-rotor poles. The flux density in the tooth tips of the excited stator of the 16/10 SRSRM is about $2 \mathrm{~T}$, which is larger than that in the same position of the $16 / 14$ SRSRM. For the 16/10 SRSRM, the flux density differs significantly between the four tooth tips of the two segmentedrotor poles, and the two teeth adjacent to the excited stator pole have higher flux densities than the other two. It means that the $16 / 10$ SRSRM is more likely to be saturated in these specific positions.

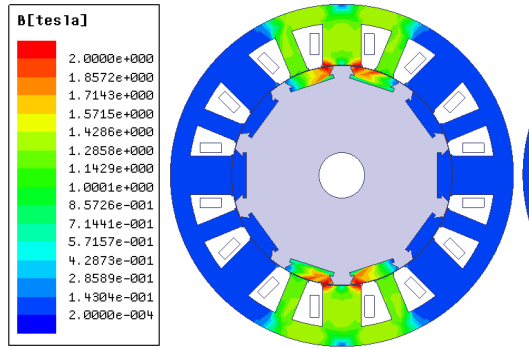

(a)

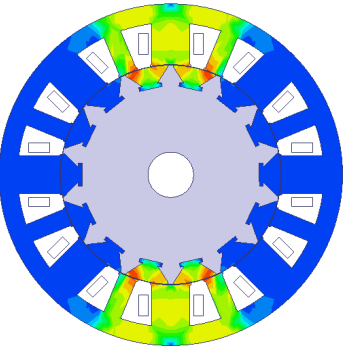

(b)
Fig. 7. Flux density at aligned position when one phase is excited with 30 A. (a) The 16/10 SRSRM. (b) The 16/14 SRSRM.

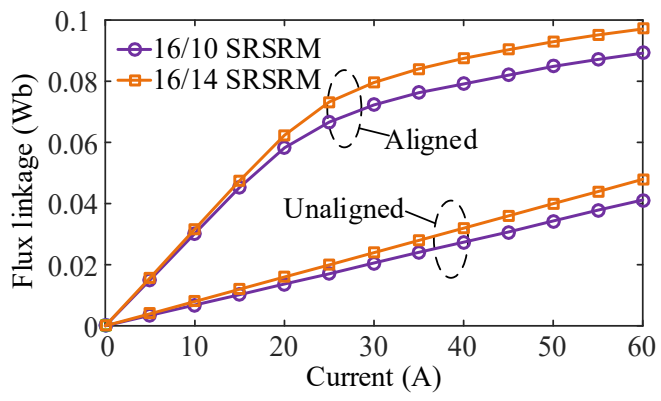

Fig. 8. Magnetization curves of the $16 / 10$ and $16 / 14$ SRSRMs at aligned and unaligned positions.

\section{B. Flux linkage and inductance}

The magnetic curves of two SRSRMs with different excitation current levels at aligned and unaligned positions, are compared in Fig. 8. Regardless of whether the motors are saturated or not, the 16/14 SRSRM exhibits $8 \%$ more flux linkage than the 16/10 SRSRM with the same current excitation at the two typical positions. When the current is about $25 \mathrm{~A}$, both SRSRMs start to saturate. Proper saturation will improve motor performance. However, oversaturation will limit further improvement of the torque even if the current is increased.

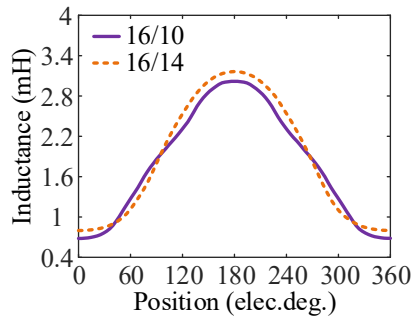

(a)

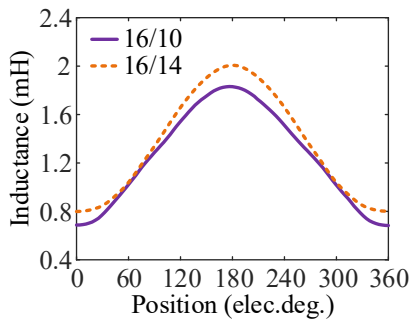

(c)

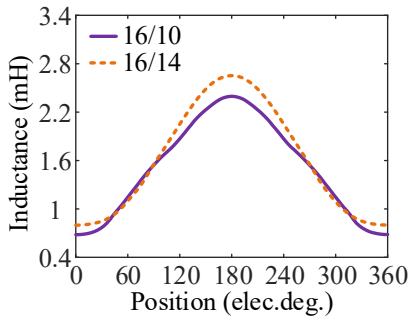

(b)

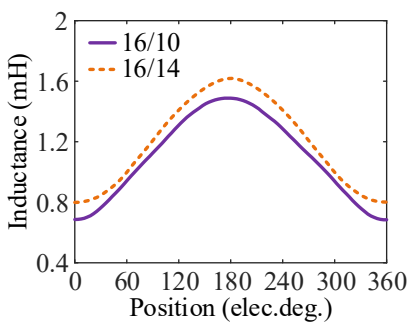

(d)
Fig. 9. Inductance characteristics of the $16 / 10$ and $16 / 14$ SRSRMs with different currents. (a) $i=15 \mathrm{~A}$. (b) $i=30 \mathrm{~A}$. (c) $i=45 \mathrm{~A}$. (d) $i=60 \mathrm{~A}$.

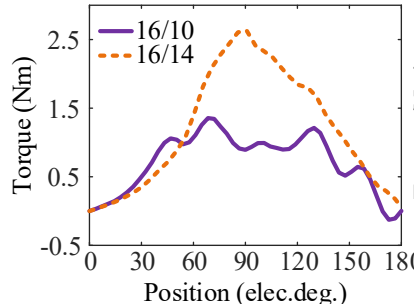

(a)

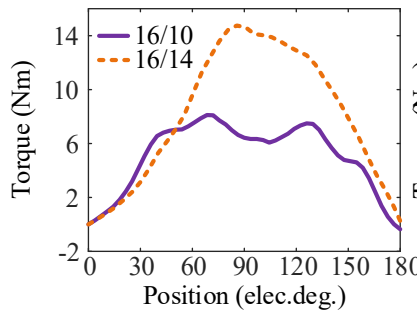

(c)

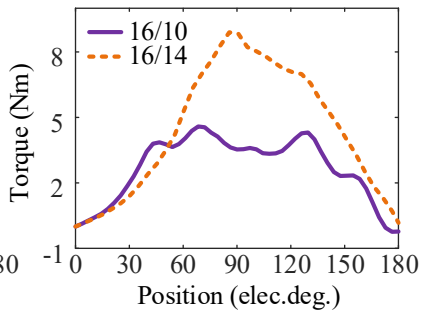

(b)

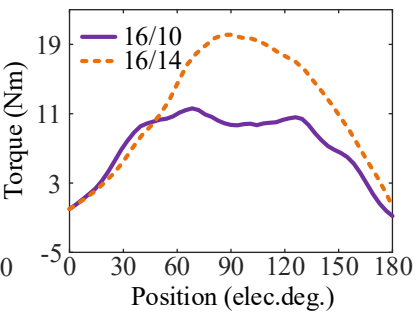

(d)
Fig. 10. Static torque of the $16 / 10$ and $16 / 14$ SRSRMs with different currents. (a) $i=15 \mathrm{~A}$. (b) $i=30 \mathrm{~A}$. (c) $i=45 \mathrm{~A}$. (d) $i=60 \mathrm{~A}$.

The phase inductance characteristics of the 16/10 and 16/14 SRSRMs with different current levels are compared in Fig. 9. It should be noted that the electrical degrees are used, so $180^{\circ}$ means the aligned position and $360^{\circ}$ means one complete cycle. It can be seen that under the low current of $15 \mathrm{~A}$, the inductance 
of the 16/10 SRSRM is slightly higher than that of the $16 / 14$ SRSRM in the partial area between the aligned and unaligned positions. With the increase of the current, this area becomes smaller and finally disappears. It can be seen that under the low current excitation, the two SRSRMs have similar phase inductance. However, under the high current excitation, as shown in Fig. 9(d), the 16/14 SRSRM exhibits higher inductance than the 16/10 SRSRM throughout the entire cycle.

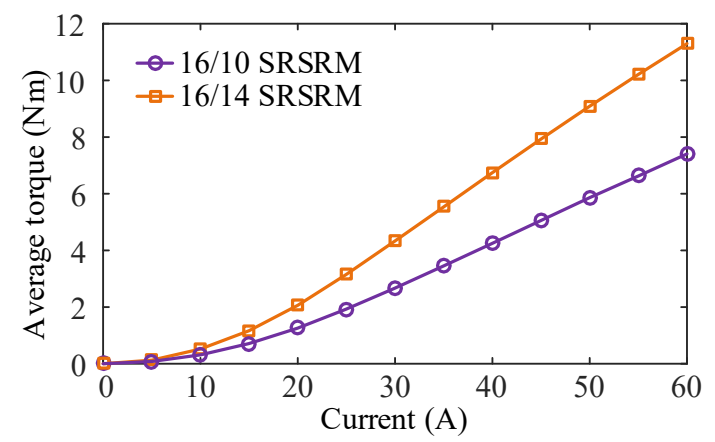

Fig. 11. Comparison of average torque under different currents.
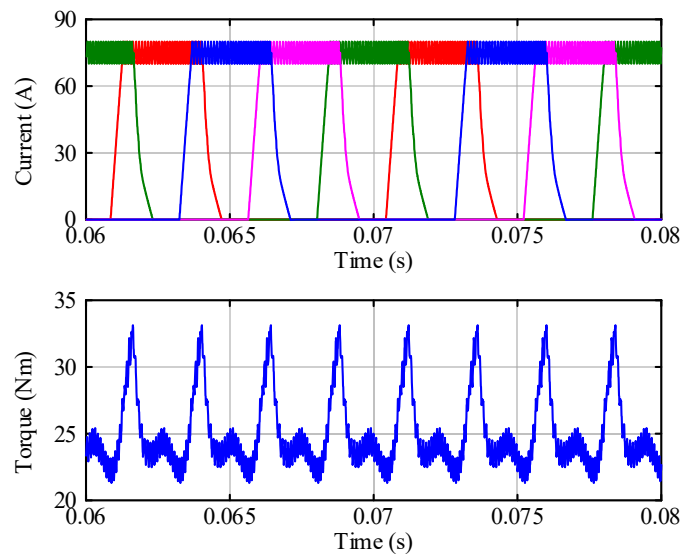

(a)
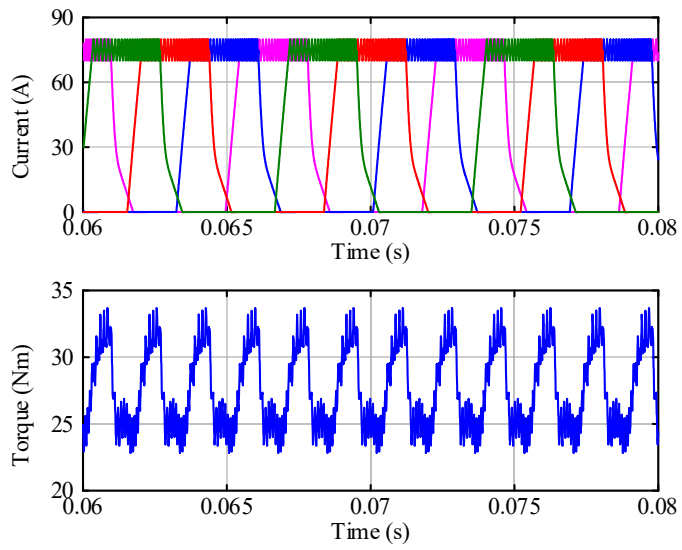

(b)

Fig. 12. Current and torque waveforms with $\mathrm{CCC}$ at $600 \mathrm{r} / \mathrm{min}$. (a) The 16/10 SRSRM. (b) The 16/14 SRSRM.

\section{Static torque}

The static torque of the two SRSRMs with one phase windings excited over one half of rotation cycle for different current levels is compared in Fig. 10. In addition, the average static torque is calculated and illustrated in Fig. 11. As shown in Fig. 10, the 16/10 SRSRM exhibits higher torque than the $16 / 14$ motor at the position ranging from $0^{\circ}$ to $50^{\circ}$ with the same current, while at the other positions, the 16/10 SRSRM produces obviously lower torque. As shown in Fig. 11, the 16/14 SRSRM produces about $40 \%$ more static average torque than the 16/10 SRSRM with the same current. That is to say, for the same torque production, the 16/14 SRSRM requires less current than the $16 / 10$ SRSRM.
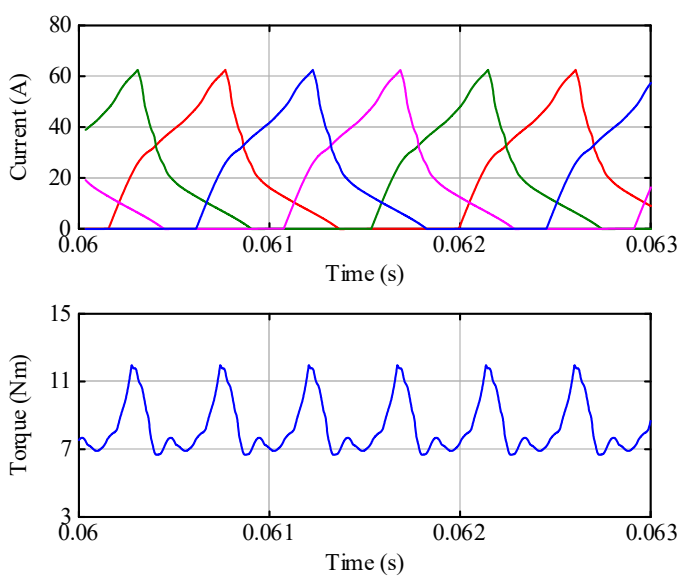

(a)
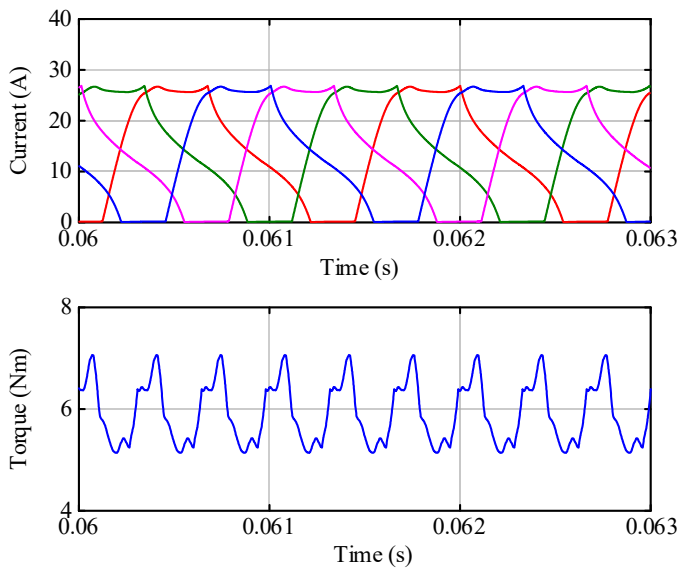

(b)

Fig. 13. Current and torque waveforms with APC at $3000 \mathrm{r} / \mathrm{min}$. (a) The 16/10 SRSRM. (b) The 16/14 SRSRM.

\section{Dynamic Performance}

The comparison of static characteristics can reflect performance of the two SRSRMs in some aspects, however, these comparison are based on the assumption that the current is constant, which is somewhat inconsistent with the actual situation. Thus, the dynamic performance will be presented in this section to further reflect the overall characteristics of the two SRSRMs. Both Matlab/Simulink and Ansoft/Maxwell are used to perform the simulation in this section. The data of flux linkage and torque characteristics in Simulink are obtained from FEA. 


\section{A. Steady-State Operation Analysis}

Figs. 12 shows the current and torque waveforms with CCC at a low speed of $600 \mathrm{r} / \mathrm{min}$, respectively. The reference current of one phase is $75 \mathrm{~A}$, thus chopping current of each pole winging is $37.5 \mathrm{~A}$. In order to achieve a fair comparison, the conduction angles of two SRSRMs are both set as 150 electrical degrees. Thus, the turn-on and turn-off angles of the 16/10 SRSRM are fixed at $-3^{\circ}$ and $12^{\circ}$ mechanical angles, and those of the 16/14 SRSRM are fixed at $0^{\circ}$ and $10.71^{\circ}$ mechanical angels. As shown in Fig. 12, the phase currents of the two SRSRMs are almost the same due to the CCC mode at the low speed. The different rotation periods lead to the distinct frequencies of current and torque.

Fig. 13 shows the current and torque waveforms with APC at a high speed of $3000 \mathrm{r} / \mathrm{min}$, respectively. It can be found that the 16/10 SRSRM can produce larger torque than the 16/14 SRSRM with higher current. This is because the phase conduction time of the 16/10 SRSRM is longer than that of the 16/14 SRSRM under the same speed. Table III lists some essential characteristics of the two motors achieved from the above simulations. It can be seen that the 16/14 SRSRM has over $16 \%$ and $48 \%$ less torque ripple than the $16 / 10$ SRSRM under CCC mode at $600 \mathrm{r} / \mathrm{min}$ and APC mode at $3000 \mathrm{r} / \mathrm{min}$, respectively. Both topologies have greatly reduced the torque ripple compared to the conventional SRMs [12]. The 16/10 SRSRM exhibits higher torque and power densities at high speed. While at low speed operation, the 16/14 SRSRM has better torque and power density characteristics. In summary, at low speed, the 16/14 SRSRM exhibits better characteristics than the 16/10 SRSRM, while the 16/10 SRSRM performs better at high speed.

In addition, for further comparison, the torque and power versus speed of the two SRSRMs under the same condition are carried out, as shown in Fig. 14. It can be seen that the 16/10 SRSRM can provide more torque and power under the high speed, while the torque and power performances of the 16/14 SRSRM are better when the speed lower than $1000 \mathrm{r} / \mathrm{min}$.

TABLE III

SUMMARY OF STEADY-STATE PERFORMANCE OF TwO SRRMS

\begin{tabular}{lcccc}
\hline \hline & \multicolumn{2}{c}{$16 / 10$ SRSRM } & \multicolumn{2}{c}{$16 / 14$ SRSRM } \\
\cline { 2 - 5 } Control modes & CCC & APC & CCC & APC \\
\hline Speed (r/min) & 600 & 3000 & 600 & 3000 \\
RMS phase current (A) & 42.12 & 26.10 & 44.33 & 17.34 \\
Average torque $(\mathrm{Nm})$ & 25.14 & 8.39 & 27.61 & 5.90 \\
Torque ripple $(\%)$ & 47.06 & 63.17 & 39.50 & 32.7 \\
Torque per ampere $(\mathrm{Nm} / \mathrm{A})$ & 0.60 & 0.32 & 0.62 & 0.34 \\
Torque density $(\mathrm{Nm} / \mathrm{kg})$ & 3.69 & 1.23 & 3.90 & 0.83 \\
Output power $(\mathrm{W})$ & 1580 & 2630 & 1735 & 1854 \\
Output power density $(\mathrm{W} / \mathrm{kg})$ & 233 & 386 & 245 & 262 \\
Copper loss $(\mathrm{W})$ & 432.87 & 166.22 & 479.50 & 73.36 \\
\hline \hline
\end{tabular}

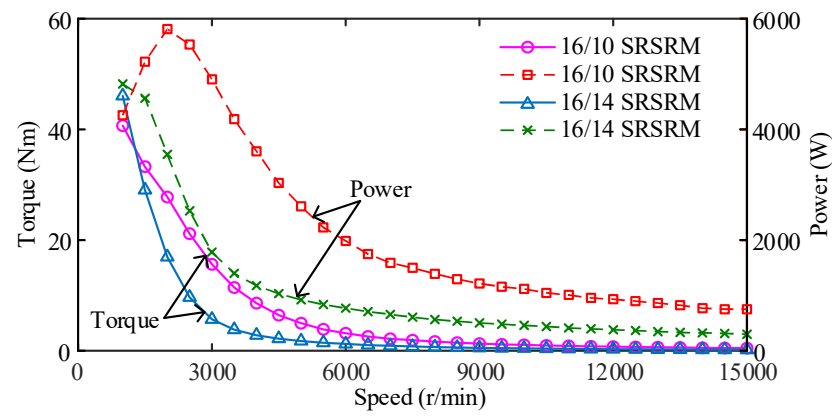

Fig. 14. Torque and power versus speed characteristics.

\section{B. Startup Performance Analysis}

For the BSG application, it is necessary to evaluate the startup operation of the motors. The transient startup performances of the two SRSRMs are compared, as shown in Fig. 15. The reference current is $75 \mathrm{~A}$, the conduction angles of two SRSRMs are both set as 150 electrical degrees, and the load torque is $1 \mathrm{Nm}$. The rotor speed of the 16/14 SRSRM rises faster than that of the 16/10 SRSRM at the beginning of the startup, but then the acceleration of the 16/14 SRSRM drops faster than that of the 16/10 SRSRM. The final steady speed of the 16/10 SRSRM is higher than that of the 16/14 SRSRM, and the rise-up time of the two SRSRMs are almost the same. That is to say, the 16/10 SRSRM has faster acceleration and higher final steady state speed.
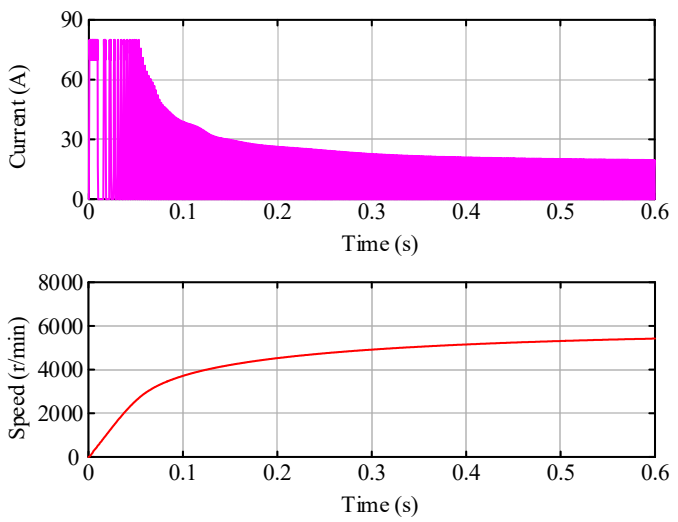

(a)
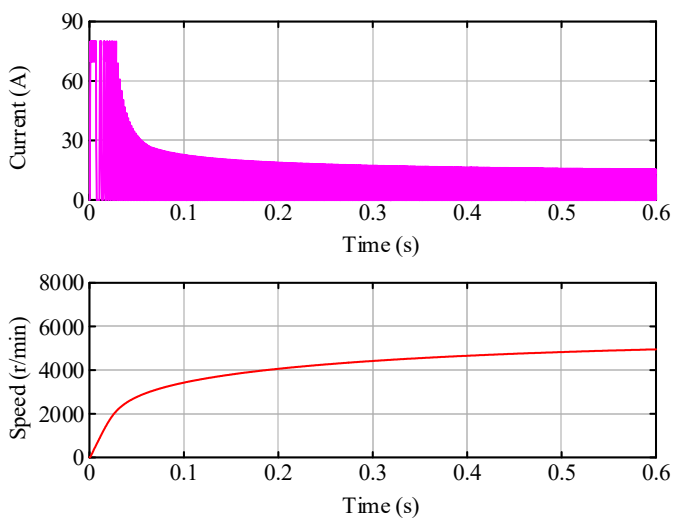

(b)

Fig. 15. Comparison of startup performance. (a) The 16/10 SRSRM. (b) The 16/14 SRSRM. 


\section{Efficiency Analysis}

The efficiency maps of the two SRSRMs are compared in Fig. 16. It can be seen that the $16 / 10$ SRSRM has higher efficiency when the speed is above $6000 \mathrm{r} / \mathrm{min}$, while the $16 / 14$ SRSRM is more efficient under low speed range. The high efficiency area of the $16 / 10$ SRSRM, ranging from 5000 to $15000 \mathrm{r} / \mathrm{min}$, is obviously larger than that of the 16/14 SRSRM, ranging from 3000 to $6000 \mathrm{r} / \mathrm{min}$. The reason for the difference in efficiency can be explained by the core loss maps shown in Fig.17. As shown, the core loss of the 16/14 SRSRM is almost twice of that of the 16/10 SRSRM, especially obvious in high-speed range. In summary, the 16/10 SRSRM exhibits better efficiency performance in the high speed range while the 16/14 SRSRM is better in low speed range. Considering the range of the high efficiency area and the maximum efficiency, the 16/10 SRSRM is more efficiency for the actual application.

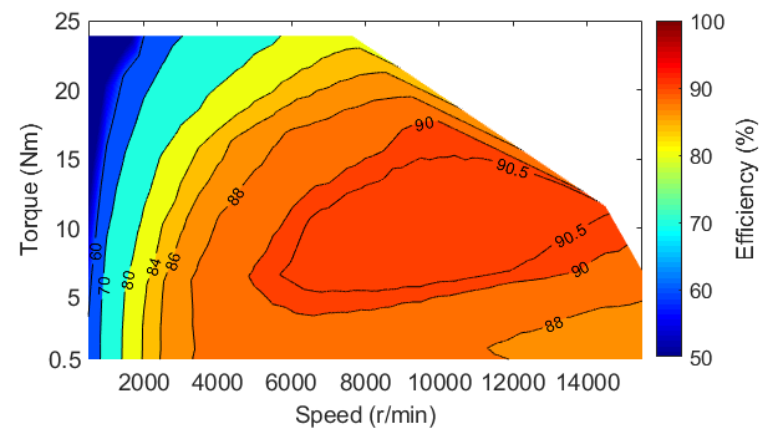

(a)

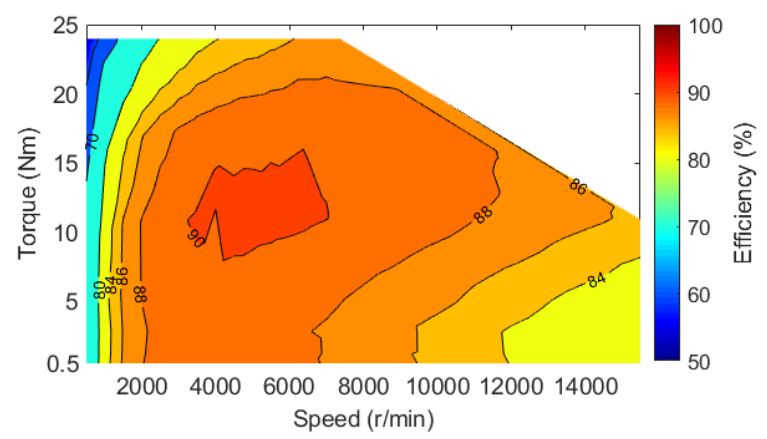

(b)

Fig. 16. Comparison of efficiency maps. (a) The 16/10 SRSRM. (b) The 16/14 SRSRM.

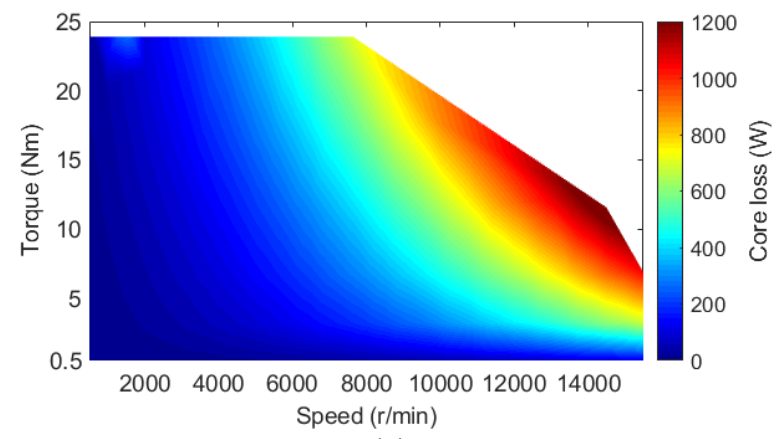

(a)

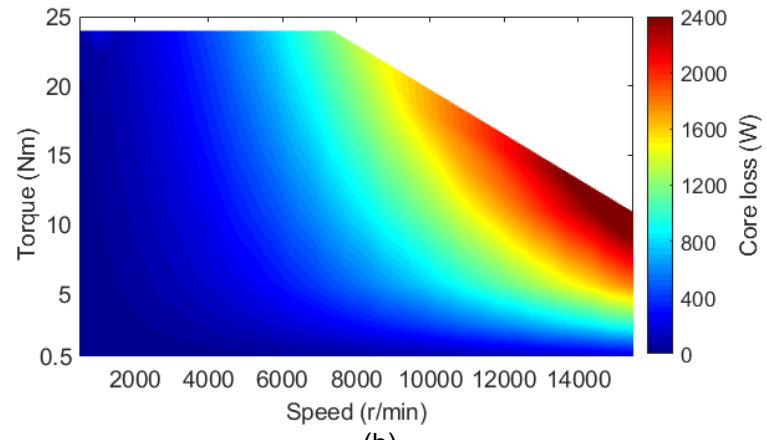

(b)

Fig. 17. Comparison of core loss maps. (a) The 16/10 SRSRM. (b) The 16/14 SRSRM.

\section{Performances under starter and braking modes}

Fig. 18 shows the comparison of the speed response under the starter mode. The conduction angles of two SRSRMs are both set as 150 electrical degrees and the load torque is $24 \mathrm{Nm}$. As shown, the 16/14 SRSRM reaches the steady speed in $0.1 \mathrm{~s}$, which is faster than the 16/10 SRSRM which requires about 0.2 s. The steady speed of the $16 / 10$ SRSRM can achieve higher than $1350 \mathrm{r} / \mathrm{min}$ while that of the $16 / 14$ SRSRM is $1200 \mathrm{r} / \mathrm{min}$. It means that the $16 / 10$ SRSRM can drive the engine up to a higher speed, which is better for the engine ignition performance.

The power generation performances of the two SRSRMs under braking mode are shown in Table IV. The turn-on and turn-off angles of the $16 / 10$ SRSRM are set as $14^{\circ}$ and $28^{\circ}$, respectively, and those of the $16 / 14$ SRSRM are set as $11^{\circ}$ and $21^{\circ}$. It can be seen that the $16 / 10$ SRSRM can provide higher generated power but lower efficiency than the 16/14 SRSRM.

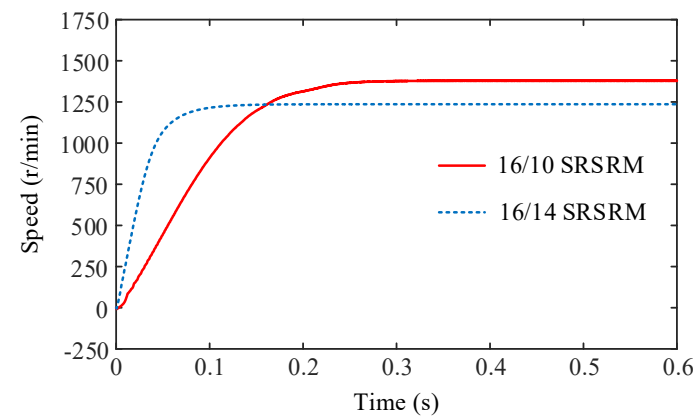

Fig. 18. Comparison of speed response under starter mode.

TABLE IV

POWER GENERATION PERFORMANCE OF TwO SRRMS

\begin{tabular}{ccccc}
\hline \hline & \multicolumn{2}{c}{$16 / 10$ SRSRM } & \multicolumn{2}{c}{ 16/14 SRSRM } \\
\cline { 2 - 5 } Speed (r/min) & $\begin{array}{c}\text { Power } \\
(\mathrm{kW})\end{array}$ & $\begin{array}{c}\text { Efficiency } \\
(\%)\end{array}$ & $\begin{array}{c}\text { Power } \\
(\mathrm{kW})\end{array}$ & $\begin{array}{c}\text { Efficiency } \\
(\%)\end{array}$ \\
\hline 3000 & 3.77 & 83.1 & 3.24 & 90.0 \\
4000 & 3.05 & 88.7 & 2.55 & 91.7 \\
5000 & 2.53 & 90.4 & 2.06 & 92.5 \\
6000 & 2.14 & 90.8 & 1.83 & 92.7 \\
7000 & 1.87 & 91.0 & 1.56 & 92.8 \\
8000 & 1.59 & 90.3 & 1.37 & 92.7 \\
9000 & 1.43 & 90.1 & 1.23 & 92.5 \\
10000 & 1.29 & 90.0 & 1.08 & 92.4 \\
11000 & 1.19 & 90.0 & 1.03 & 92.3 \\
12000 & 1.10 & 89.7 & 0.93 & 92.0 \\
\hline \hline
\end{tabular}




\section{EXPERIMENTAL VALIDATION}

In order to verify the accuracy of simulation and the aforementioned analyses, a 16/10 SRSRM prototype with the selected parameters and dimensions is manufactured as shown in Fig. 19, due to the better performance and higher efficiency at high speed range, better startup performance, comprehensive performances under starter and braking modes, and simpler manufacturing process. The total cost of the motor is over $\$ 2000$.

\section{A. Static Performance Validation}

Fig. 20 shows a test platform for the static characteristics of the SRSRM. The torque can be measured by using the torque and speed sensor when the power supply provides the steady current.

Fig. 21 shows the comparison between simulation and measured phase flux linkages of the 16/10 SRSRM at aligned and unaligned positions. The flux linkage of measured results at the two specific positions is slightly lower than that of simulation, mainly due to the manufacturing deviation of the motor. The simulation and measured static torque with current of $20 \mathrm{~A}$ are compared in Fig. 22.

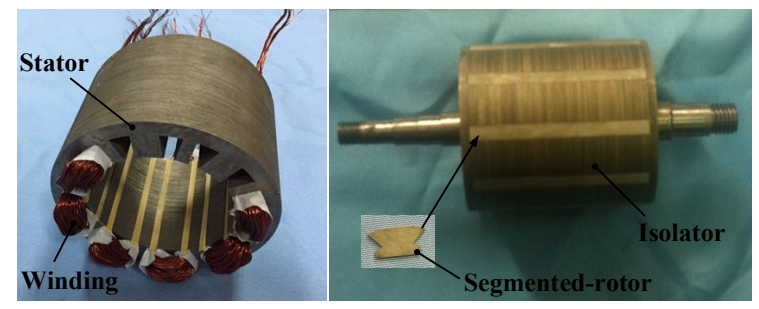

Fig. 19. The prototype of the $16 / 10$ SRSRM.

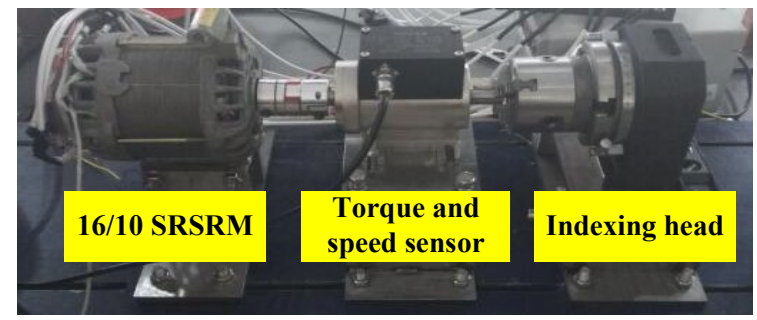

Fig. 20. Devices and platform for static characteristics.

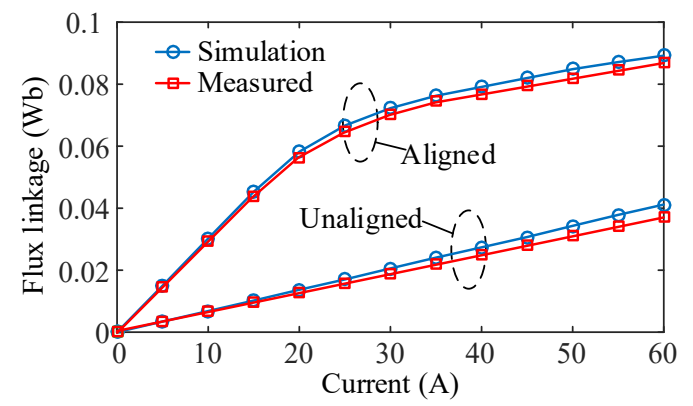

Fig. 21. Simulation and measured results of flux linkage for the $16 / 10$ SRSRM.

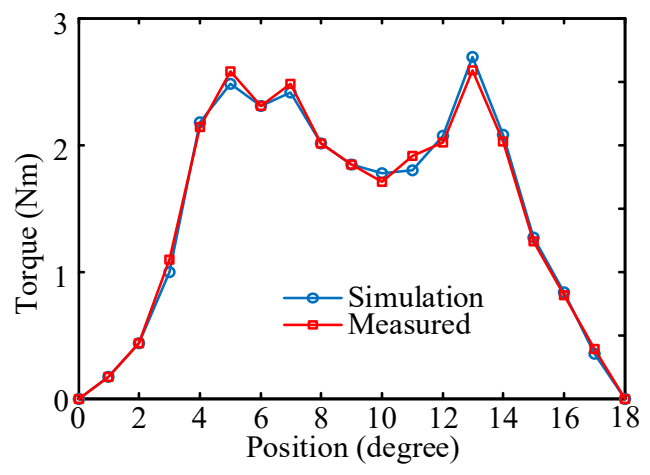

Fig. 22. Simulation and measured results of static torque for the $16 / 10$ SRSRM with current of $20 \mathrm{~A}$.

\section{B. Dynamic Performance Validation}

Fig. 23 shows a test platform for the dynamic characteristics. The tested 16/10 SRSRM, torque and speed sensor, and magnetic power brake are connected by two couplings. The position is detected by the Hall sensor ATS675LSE. The signals captured by the position and current sensors are sent to the dSPACE. Then the signals are analyzed in the dSPACE, such as angle calculation, current protection and the control. Finally, the drive signals are sent to the IGBT to control the asymmetrical half bridge circuit.

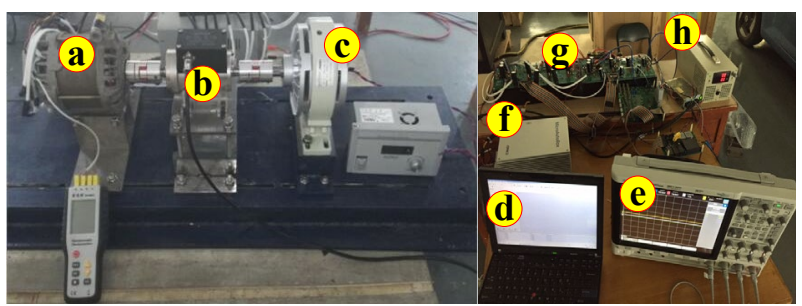

Fig. 23. Devices and platform for dynamic characteristics. (a) The 16/10 SRSRM. (b) Torque and speed sensor. (c) Magnetic power brake. (d) PC. (e) Oscilloscope. (f) dSPACE. (g) Power converter and driving circuit. (h) Power supply.

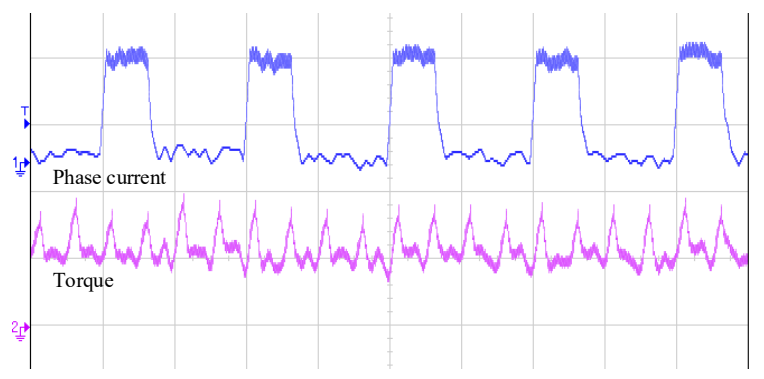

Fig. 24. Experiment results with CCC mode at $600 \mathrm{r} / \mathrm{min}$.

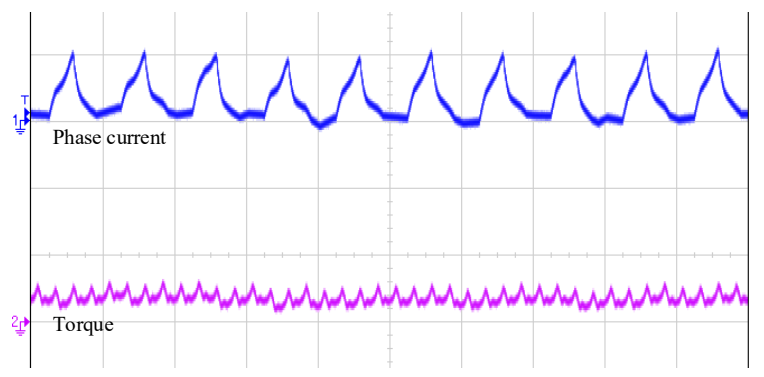


Fig. 25. Experiment results with APC mode at $3000 \mathrm{r} / \mathrm{min}$.

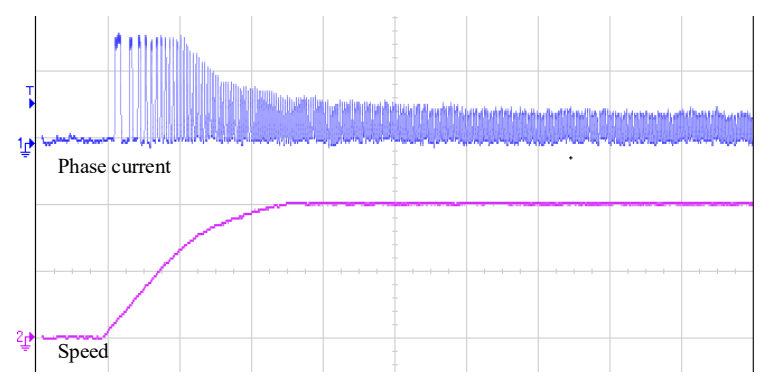

Fig. 26. Experiment results for startup performance.

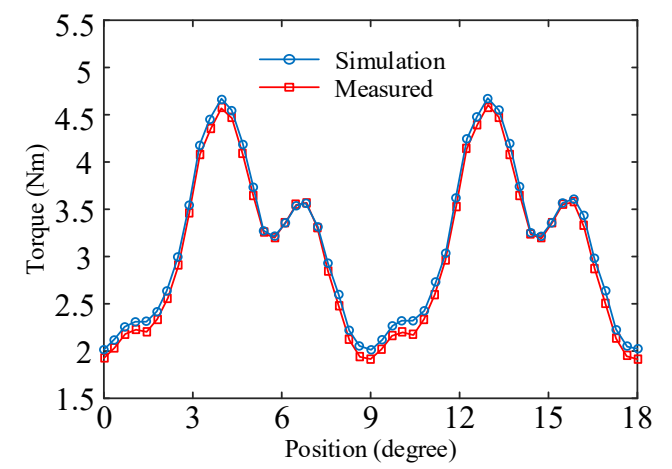

Fig. 27. Simulation and experiment results with APC at $6000 \mathrm{r} / \mathrm{min}$.

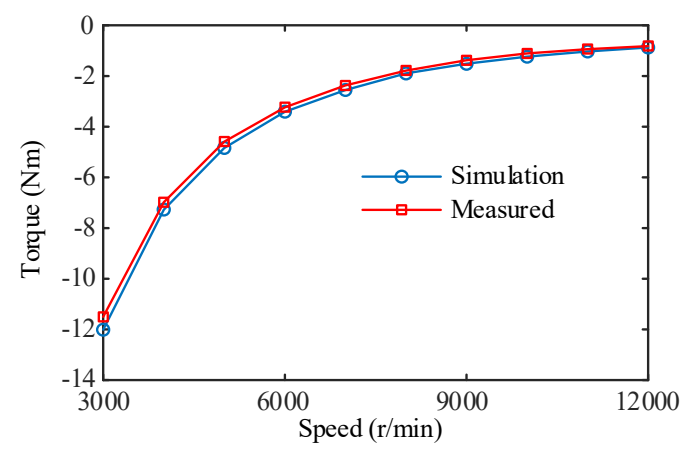

Fig. 28. Average torque comparison of simulation and measured results under braking mode.

The steady-state performances of the 16/10 SRSRM are tested to verify the simulation accuracy. Fig. 24 shows the experiment results with $\mathrm{CCC}$ mode at $600 \mathrm{r} / \mathrm{min}$. The phase voltage is $60 \mathrm{~V}$ and the phase chopping current is $75 \mathrm{~A}$. The measured average torque can achieve $25.47 \mathrm{Nm}$, which is close to the simulation result. Fig. 25 shows the experiment results with APC mode at $3000 \mathrm{r} / \mathrm{min}$. The turn-on angle and turn-off angles are fixed at $-3^{\circ}$ and $12^{\circ}$, respectively. The measured RMS current and average torque are $24.84 \mathrm{~A}$ and $8.27 \mathrm{Nm}$, respectively. The measured results agree well with simulated values. Fig. 26 shows the experiment results for startup performance. The voltage is $60 \mathrm{~V}$ and the load torque is $1 \mathrm{Nm}$. the rise-up time is approximately $1.3 \mathrm{~s}$, and the steady speed can finally achieve over $5000 \mathrm{r} / \mathrm{min}$. The simulation and experimental torque curves at the rated speed are compared in Fig. 27. Besides, the comparison of simulation and measured average torque with different speed under braking mode is shown in Fig. 28. The measured results agree well with the simulation results, which verify the aforementioned predictions.

\section{CONCLUSION}

In this paper, the design principles of SRSRMs, including some new restrictions of the pole numbers and structures, were presented. Two SRSRMs with $16 / 10$ and 16/14 stator/rotor poles were comprehensively evaluated and compared. In order to achieve a fair comparison, the two SRSRMs were optimized independently. The overall performances including the magnetic characteristics, steady-state operation, startup operation, efficiency, and performances under starter and braking modes of the 16/10 and 16/14 SRSRMs, were compared. Based on simulation results and experimental validation, five main conclusions can be drawn as follows.

1) The $16 / 10$ and $16 / 14$ SRSRMs have similar flux distributions. The 16/10 SRSRM is more likely to be saturated in the tooth tips of the excited stator poles and its relative segmented-rotors. The 16/14 SRSRM exhibits higher flux linkage and static torque than the 16/10 SRSRM under the same current excitation.

2) In low speed range, the $16 / 14$ SRSRM exhibits better characteristics than the 16/10 SRSRM, such as larger torque, lower torque ripple, and higher torque and power densities. While in high speed range, the 16/10 SRSRM can provide better torque and power density.

3) The 16/10 SRSRM has faster acceleration and higher final steady state speed than the 16/14 SRSRM under the same startup condition. In addition, the rise-up time of the two SRSRMs is almost the same.

4) The 16/10 SRSRM exhibits higher efficiency in the most feasible speed range, especially in high speed range. The core losses of the 16/10 SRSRM is lower than that of the 16/14 SRSRM under the same speed. The high efficiency area of 16/10 SRSRM is about three times that of the 16/14 SRSRM. Thus, the 16/10 SRSRM is more efficiency for the actual application.

5) Under the start mode, the 16/14 SRSRM can rise faster to the steady speed than the $16 / 10$ SRSRM, while the $16 / 10$ SRSRM can drive the engine up to a higher speed. Under the braking mode, the 16/10 SRSRM can provide higher generated power than the 16/14 SRSRM, while the efficiency of $16 / 14$ SRSRM is a bit higher.

\section{REFERENCES}

[1] N., R. Patel, V. A. Shah and M. M. Lokahande, "A novel approach to the design and development of 12/15 radial field $\mathrm{C}$-core switched reluctance motor for implementation in electric vehicle application", IEEE Trans. Veh Technol., vol. 67, no. 9, pp: 8031-8040, Sep. 2018.

[2] E., Öksüztepe, "In-wheel switched reluctance motor design for electric vehicles by using a Pareto-based multiobjective differential evolution algorithm", IEEE Trans. Veh Technol., vol. 66, no. 6, pp: 4706-4715, Jun. 2017.

[3] X. Yuan and J. Wang, "Torque distribution strategy for a front- and rearwheel-driven electric vehicle", IEEE Trans. Veh Technol., vol. 61, no. 8, pp. 3365-3374, Oct. 2012.

[4] Z. Shi, X. Sun, Y. Cai, Z. Yang, G. Lei, Y. Guo, and J. Zhu, "Torque Analysis and Dynamic Performance Improvement of a PMSM for EVs by Skew Angle Optimization," IEEE Trans. Appl. Supercon., vol. 29, no. 2, pp. 1-5, 2019.

[5] S. S. R. Bonthu, J. Baek, and M. Z. Islam, "Optimal design of five phase 
permanent magnet assisted synchronous reluctance motor for integrated starter generator application", IEEE Int. Elect. Machines and Drives Conf., pp. 433-439, 2015.

[6] S. Chen, B. Lequesne, R. R. Henry, Y. Xue, and J. J. Ronning, "Design and testing of a belt-driven induction starter-generator", IEEE Trans. Ind. Appl., vol. 38, no. 6, pp. 1525-1533, Nov./Dec. 2002.

[7] X. Sun, L. Chen, H. Jiang, Z. Yang, J. Chen, and W. Zhang. "Highperformance control for a bearingless permanent magnet synchronous motor using neural network inverse scheme plus internal model controllers." IEEE Trans. on Ind. Electron., vol. 63, no. 6, pp. 3479 3488, 2016.

[8] T. Raminosoa, B. Blunier, D. Fodorean, and A. Miraoui, "Design and optimization of a switched reluctance motor driving a compressor for a PEM fuel-cell system for automotive applications", IEEE Trans. Ind. Electron., vol. 57, no. 9, pp. 2988-2997, Sep. 2010.

[9] H. Chen, and J. J. Gu, "Implementation of the three-phase switched reluctance machine system for motors and generators", IEEE/ASME Trans. Mech., vol. 15, no. 3, pp. 421-432, Jun. 2010.

[10] C. Lee, R. Krishnan, and N. S. Lobo, "Novel two-phase switched reluctance machine using common-pole E-core structure: concept, analysis, and experimental verification", IEEE Trans. Ind. Appl., vol. 45, no. 2, pp. 703-711, Mar./Apr. 2009.

[11] C. Lee and R. Krishnan, "New designs of a two-phase E-core switched reluctance machine by optimizing the magnetic structure for a specific application: concept, design, and analysis", IEEE Trans. Ind. Appl., vol. 45, no. 5, pp. 1804-1814, Sep./Oct. 2009.

[12] H. Eskandari and M. Mirsalim, "An improved 9/12 two-phase E-core switched reluctance machine”, IEEE Trans. Energy Convers., vol. 28, no. 4, pp. 951-958, Dec. 2013.

[13] W. Ding, Y. H. Hu, and L. Wu, "Analysis and development of novel three-phase hybrid magnetic paths switched reluctance motors using modular and segmental structures for EV applications", IEEE/ASME Trans. Mech., vol. 20, no. 5, pp. 2437-2451, Oct. 2015.

[14] L. Szabo and M. Ruba, "Segmental stator switched reluctance machine for safety-critical applications" IEEE Trans. Ind. Appl., vol. 48, no. 6, pp. 2223-2229, Nov. 2012.

[15] S. R. Mousavi-Aghdam, M. R. Feyzi, and N. Bianchi, "Design and analysis of a novel high-torque stator-segmented SRM", IEEE Trans. Ind. Electron., vol. 63, no. 3, pp. 1458-1466, Mar. 2016.

[16] B. C. Mecrow, E. A. El-Kharashi, J. W. Finch, and A. G. Jack, "Preliminary performance evaluation of switched reluctance motors with segmental rotors", IEEE Trans. Energy Convers., vol. 19, no. 4, pp. 679686, Dec. 2004.

[17] Z. Y. Xu, D. H. Lee, and J. W. Ahn, "Design and operation characteristics of a novel switched reluctance motor with a segmental rotor", IEEE Trans. Ind. Appl., vol. 52, no. 3, pp. 2564-2572, May. 2016.

[18] J. D. Widmer, R. Martin, and B. C. Mecrow, "Optimization of an 80-kW segmental rotor switched reluctance machine for automotive traction", IEEE Trans. Ind. Appl., vol. 51, no. 4, pp. 2990-2999, Jul. 2015.

[19] V. R. Vandana and B. G. Fernandes, "Design methodology for highperformance segmented rotor switched reluctance motors", IEEE Trans. Energy Convers., vol. 30, no. 1, pp. 11-21, Mar. 2015.

[20] J. D. Widmer, and B. C. Mecrow, "Optimized segmental rotor switched reluctance machines with a greater number of rotor segments than stator slots," IEEE Trans. Ind. Appl., vol. 49, no. 4, pp. 1491-1498, Jul. 2013.

[21] R. Madhavan and B. G. Fernandes, "Axial flux segmented SRM with a higher number of rotor segments for electric vehicles", IEEE Trans. Energy Convers., vol. 28, no. 1, pp. 203-213, Mar. 2013.

[22] B. Bilgin, A. Emadi, and M. Krishnamurthy, "Design considerations for switched reluctance machines with a higher number of rotor poles", IEEE Trans. Ind. Electron., vol. 59, no. 10, pp. 3745-3756, Oct. 2012.

[23] W. Ding, S. Yang, and Y. F. Hu, "Development and investigation on segmented-stator hybrid-excitation switched reluctance machines with different rotor pole numbers", IEEE Trans. Ind. Electron., vol. 65, no. 5, pp. 3784-3794, May 2018.

[24] P. C. Desai, M. Krishnamurthy, N. Schofield, and A. Emadi, "Novel switched reluctance machine configuration with higher number of rotor poles than stator poles: concept to implementation", IEEE Trans. Ind. Electron., vol. 57, no. 2, pp. 649-659, Feb. 2010.

[25] X. Sun, Z. Xue, S. Han, L. Chen, "Design and analysis of a novel 16/10 segmented rotor SRM for $60 \mathrm{~V}$ belt-driven starter generator", J. Magnetics, vol. 21, no. 3, pp. 393-398, Sep. 2016.

[26] X. Sun, Z. Xue, S. Han, L. Chen, X. Xu, "Comparative study of faulttolerant performance of a segmented rotor SRM and a conventional
SRM", Bulletin of the Polish Academy of Sciences Technical Sciences, vol. 65 , no. 3, pp. 375-381, Jan. 2017.

[27] F. Fleming, and C. Edrington, "Real-time emulation of switched reluctance machines via magnetic equivalent circuits," IEEE Trans. Ind. Electron., vol. 63, no. 6, pp. 3366-3376, Jun. 2016.

[28] X. Sun, Y. Shen, S. Wang, G. Lei, Z. Yang, and S. Han, "Core losses analysis of a novel 16/10 segmented rotor switched reluctance BSG motor for HEVs using nonlinear lumped parameter equivalent circuit model", IEEE/ASME Trans. Mechatronics, vol. 23, no. 2, pp. 747-757, Apr. 2018.

[29] P. J. Lawrenson, J. M. Stephenson, P. T. Blenkinsop, J. Corda, and N. N. Fulton, "Variable-speed switched reluctance motors," Inst. Elect. Eng. Pro.-Electr. Power Appl., vol. 127, Pt. B, no. 4, pp. 253-265, Jul. 1980.

[30] H. Wu, Theory and control technology of switched reluctance motor system. Beijing, China. Jul. 2010.

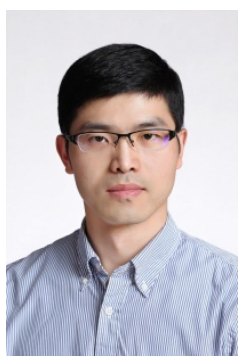

Xiaodong Sun (M'12-SM'18) received the B.Sc. degree in electrical engineering, and the M.Sc. and Ph.D. degrees in control engineering from Jiangsu University, Zhenjiang, China, in 2004, 2008, and 2011, respectively.

Since 2004, he has been with Jiangsu University, where he is currently a Professor with the Automotive Engineering Research Institute. From 2014 to 2015, he was a Visiting Professor with the School of Electrical, Mechanical, and Mechatronic Systems, University of Technology Sydney, Sydney, Australia. His current teaching and research interests include electrical machines and drives, drives and control for electric vehicles, and intelligent control. $\mathrm{He}$ is the author or coauthor of more than 80 refereed technical papers and one book, and he is the holder of 36 patents in his areas of interest.

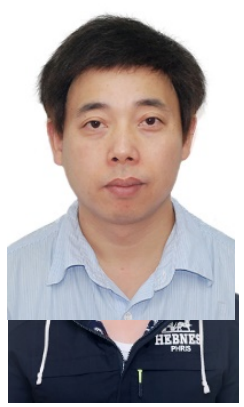

Kaikai Diao (S'18) was born in Zhenjiang, Jiangsu, China, in 1994. He received the B.S. degree in vehicle engineering from Jiangsu University, Zhenjiang, China, in 2017, and he is currently working toward the Ph.D. degree in Jiangsu University, Zhenjiang, China.

His current research interests include design, optimization, magnetic equivalent circuits modeling, control, and loss analysis of switched reluctance motors for automobile application.

Gang Lei (M'14) received the B.S. degree in Mathematics from Huanggang Normal University, China, in 2003, the M.S. degree in Mathematics and Ph.D. degree in Electrical Engineering from Huazhong University of Science and Technology, China, in 2006 and 2009, respectively. He is currently a senior lecturer at the School of Electrical and Data Engineering, University of Technology Sydney (UTS), Australia. His research interests include design optimization and control of electrical drive systems and renewable energy systems.

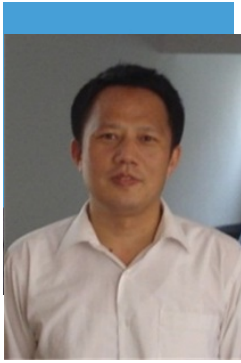

Long Chen received the B.Sc. and Ph.D. degrees in mechanical engineering from Jiangsu University, Zhenjiang, China, in 1982 and 2006, respectively.

$\mathrm{He}$ is currently a Professor with the Automotive Engineering Research Institute, Jiangsu University. His areas of interest include electric vehicles, electric drives, simulation and control of vehicle dynamic performance, vehicle operation, and transport planning.

Youguang Guo (S'02-M'05-SM'06) received the B.E. degree from Huazhong University of Science and Technology, China in 1985, the 
M.E. degree from Zhejiang University, China in 1988, and the Ph.D.

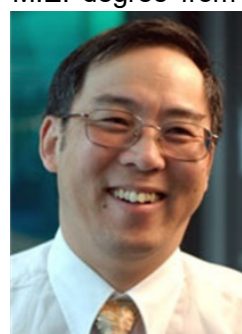
degree from University of Technology, Sydney (UTS), Australia in 2004, all in electrical engineering. $\mathrm{He}$ is currently an associate professor at the School of Electrical and Data Engineering, University of Technology Sydney (UTS). His research fields include measurement and modeling of properties of magnetic materials, numerical analysis of electromagnetic field, electrical machine design optimization, power electronic drives and control.

Jianguo Zhu (S'93-M'96-SM'03) received the B.E. degree in 1982 from Jiangsu Institute of Technology, Jiangsu, China, the M.E. degree in 1987 from Shanghai University of Technology, Shanghai, China, and the Ph.D. degree in 1995 from the University of Technology Sydney (UTS), Sydney, Australia, all in electrical engineering. He was appointed a lecturer at UTS in 1994 and promoted to full professor in 2004 and Distinguished Professor of Electrical Engineering in 2017. At UTS, he has held various leadership positions, including the Head of School for School of Electrical, Mechanical and Mechatronic Systems and Director for Centre of Electrical Machines and Power Electronics. In 2018, he joined the University of Sydney, Australia, as a full professor and Head of School for School of Electrical and Information Engineering. His research interests include computational electromagnetics, measurement and modelling of magnetic properties of materials, electrical machines and drives, power electronics, renewable energy systems and smart micro grids. 